eCommons@AKU

Book Chapters

January 2009

\title{
E-health in international networks: New opportunities for collaboration
}

\author{
Shariq Khoja \\ Aga Khan University, Institute for Educational Development, Karachi \\ Azra Naseem \\ Aga Khan University, Institute for Educational Development, Karachi
}

Follow this and additional works at: http://ecommons.aku.edu/book_chapters

Part of the International and Comparative Education Commons, Other Educational

Administration and Supervision Commons, and the Other Teacher Education and Professional

Development Commons

\section{Recommended Citation}

Khoja, S., \& Naseem, A. (2009). E-health in international networks: New opportunities for collaboration. In R. Wootton, N. G. Patil, R. E. Scott, \& K. Ho (Eds.), Telehelath in the developing world (pp. 287-296). Ottawa: International Development Research Centre. 


\section{E-health in international networks: New opportunities for collaboration

\author{
Shariq Khoja and Azra Naseem
}

\section{Introduction}

In recent years, there has been a substantial reduction in the availability of health professionals in developing countries, which has been accompanied by a rise in the demand for high-quality health care. This combination has forced health care institutions to collaborate and share their resources to provide comprehensive, high-quality and accessible health care at a reasonable cost.

The Aga Khan Development Network (AKDN) is an international network that comprises several institutions, working for the development of poor nations in Asia and Africa, in social development (health, education and housing), disaster relief, economic development and preservation of cultures. Most of the development in the health sector is carried out through the Aga Khan Health Services (AKHS) and the Aga Khan University (AKU).

The AKHS operates a private, not-for-profit health care system. It includes more than 200 health care facilities, including 9 hospitals. The AKHS provides primary health care and curative medical care in Afghanistan, India, Kenya, Pakistan and Tanzania. It also provides technical assistance to governments in health service delivery in Kenya, Syria and Tajikistan. The community health programmes of the AKHS are designed to reach vulnerable groups in society, especially childbearing women and young children, through low-cost, proven medical technologies. Experience has confirmed the efficacy of these services in improving health status and their costeffectiveness. ${ }^{1}$

The AKU is an international university with 11 teaching sites in 8 countries: Afghanistan, Kenya, Pakistan, Tanzania, Uganda, Syria, Egypt and the UK. The AKU is also associated with university hospitals in Pakistan and Kenya. The largest of these is the Aga Khan University Hospital, Karachi (AKUH, K), which has 542 beds and provides services to 38000 inpatients and 500000 outpatients annually. The Aga Khan University Hospital, Nairobi (AKUH, N) also provides tertiary- and secondarylevel health care services in East Africa.

The extent and scope of the AKDN's health activities require considerable networking between the different agencies. For decades, this networking was maintained 
by traditional means of communication and extensive travel by health professionals between various institutions. In the last five years, some institutions within the AKDN have begun to adopt information and communication technology (ICT) to enhance their educational, research, information exchange and health provision activities. All these activities can be grouped under the umbrella of 'e-health'. Although, e-health in the AKDN is still in its infancy, activities directed towards learning, care provision and information exchange have already begun.

\section{Benefits of e-health}

Institutions within the AKDN have shown interest in adopting e-health to enhance their education, research, information exchange and health provision activities. The following benefits are anticipated:

- Improved clinical care. An e-health network will encourage rapid adoption of e-health applications that will facilitate improved clinical care. For example, common access to clinical practice guidelines will aid standardization of care, and use of specific e-health applications such as teleconsulting will raise the confidence and skills of clinicians in rural and remote locations.

- Greater knowledge sharing. An e-health network, with an emphasis on knowledge rather than simply information, will ensure greater knowledge sharing.

- Greater scope for research. Interaction through an e-health network will enhance partnerships and sharing of resources, which will in turn contribute to a greater scope for research.

- Greater capacity building. Capacity building, in particular, will be strengthened through an e-health network. Institutions with a common focus (within or outside the AKDN) could join and contribute their respective skills and experiences.

- Administrative resilience. A successful e-health network will strengthen administrative resilience.

Although, e-health in the AKDN is still at its beginning, activities directed towards learning, care provision and information exchange have already begun. These activities are described briefly below.

\section{Learning}

The AKU and the AKHS have worked in collaboration to develop asynchronous learning for medical and nursing students, and to develop continuing medical education (CME) for health care providers. Efforts are also being made to introduce the use of live e-learning software at the AKU. Two distinct instructional settings can be identified where ICT is used for learning:

- In technology-enhanced classroom teaching, teachers use PowerPoint slides to illustrate concepts in their face-to-face lectures and later distribute them to the class by email. Students submit word-processed assignments for assessment. 
- In distance education, nurses and other health care providers, particularly in East Africa, complete formal educational programmes at remote locations. In such programmes, email messages are used, together with online discussions via videoconferencing or through web-conferencing.

There is also blended or distributed learning as a combination of these two approaches, with an increasing emphasis on the use of online learning technologies. E-learning in blended courses can take many different forms. Examples include:

- repository of learning objects

- web-based virtual learning environment

- a database of Internet links

- synchronous e-learning through Elluminate

- remote access for health professionals.

\section{Repository of learning objects}

In 2003, a searchable Library of Images was developed at the AKU. The aim was to create a repository of learning objects, which could be searched, reused and shared over the network to avoid duplication of effort in developing learning resources. Initially, the pictures and other images were digitized and catalogued with appropriate metadata information. Later, registered users, including students, faculty members, clinicians, residents and allied health staff, were also able to contribute images with associated metadata information. A committee was set up to review each contribution in order to ensure its relevance and accuracy and to avoid redundancy and duplication. Moreover, ethical issues such as concealing the identity of patients were also considered. Currently, 1500 digitized items (clinical photographs, radiological images, operative findings, microscopy slides, ECG and EEG charts, animations, and video-clips) are available ${ }^{2}$ for AKU faculty members, staff, students and other health care providers through the Internet. ${ }^{3}$ The images from the Library of Images are used in class lectures, presentations and assignments, and are also linked with course materials available via AKUMed. The material is shared with other institutions within the network with access to the AKU intranet.

\section{Web-based virtual learning environment}

The need for a system that would allow access to course information, lecture notes and a discussion forum for students of the MB BS programme was felt by the faculty at the AKU Medical College, and led to the development of an asynchronous virtual learning environment (VLE) called AKUMed. VLE refers to the components in which learners and tutors participate in online interactions of various kinds, including online learning. ${ }^{4}$ With growing numbers of faculty members using AKUMed, its popularity has increased, and similar systems are being designed for the School of Nursing and the Department of Community Health Sciences, in order to offer courses with strong online components. 


\section{Database of Internet links}

A portal with links to websites on various health-related topics has been developed. The portal is accessible through the AKU intranet and is regularly updated. It is used by the students and faculty members of the AKU.

\section{Synchronous e-learning}

Elluminate Live has been introduced as a live e-learning tool in all campuses of the AKU. It was chosen because it can be used from areas with low-bandwidth Internet connections. The software allows recording, and permits sharing of audio, video, text and image data. Elluminate also allows the use of white board and document sharing, to facilitate online discussions. Finally, it supports transfer of medical data and live teleconsultations, which may be an important feature for the AKU. Several pilot projects have been initiated in different campuses of the AKU in Asia, Africa and Europe. A summary of the pilot projects at each campus is given in Table 27.1.

\section{Remote access for health professionals}

Remote access for health staff was conceived as a structured educational programme for health care providers, which focused on problem-based learning via a web-based distance learning system. The purpose of this programme was to facilitate evidencebased practice of medicine and nursing at the Aga-Khan Hospital in Dar-es-Salaam and its five affiliated primary care centres in Tanzania. A phased approach was planned, followed by the introduction at other AKHS institutions. The web interface allows multiple threaded discussions based on specific interest areas, including subspecialties such as paediatrics, cardiology and nursing. This makes it possible for health professionals in North America to share journal articles, PowerPoint presentations, quality assurance tools and weblinks to various resources with staff in Tanzania. The long-term goal is to make this method of learning accessible to health care professionals associated with the AKHS in East Africa or with other private and public sector hospitals, to improve health care delivery in those countries.

\section{Care provision}

Two examples of telehealth in AKDN agencies are:

(1) email-based teleconsultations in Tanzania

(2) a teleradiology link in Afghanistan.

\section{Email-based teleconsultations}

In 2004, a pilot telemedicine programme began that allowed communication between doctors working at the Aga Khan Hospital in Dar-es-Salaam and clinicians in North America. The goal was to create partnerships that would improve the delivery and quality of health care in the region. The pre-defined turnaround time for queries was 24-72 hours. 
Table 27.1 Summary of the pilot projects at each AKU campus

\begin{tabular}{|c|c|c|c|c|}
\hline & AKU-IED, Karachi & AKU-CHS, Karachi & AKU-ISMC, London & $\begin{array}{l}\text { AKU-SON, Karachi and AKU-EA, } \\
\text { Nairobi }\end{array}$ \\
\hline Objective & $\begin{array}{l}\text { Understand changing needs and } \\
\text { plan accordingly }\end{array}$ & $\begin{array}{l}\text { Look into all possible options where } \\
\text { Elluminate will be useful }\end{array}$ & Gain confidence with Elluminate & $\begin{array}{l}\text { Pilot Elluminate use for continuing } \\
\text { education courses offered from } \\
\text { AKU-SON Karachi to East Africa, } \\
\text { Afghanistan and Egypt }\end{array}$ \\
\hline \multirow[t]{5}{*}{ Areas } & $\begin{array}{l}\text { Distance education courses } \\
\text { Meetings with Professional } \\
\text { Development Centres }\end{array}$ & $\begin{array}{l}\text { Work in progress (WIP) } \\
\text { Online CME course with East Africa } \\
\text { Web seminar on health problems in }\end{array}$ & $\begin{array}{l}\text { Meetings with different departments, } \\
\text { e.g. Finance, IT and Provost's } \\
\text { Office, once a month or more }\end{array}$ & $\begin{array}{l}\text { Continuing education programme } \\
\text { for practising nurses }\end{array}$ \\
\hline & \multirow[t]{4}{*}{$\begin{array}{l}\text { Other uses by faculty members in } \\
\text { teaching-related activities }\end{array}$} & $\begin{array}{l}\text { Pakistan } \\
\text { Postgraduate education } \\
\text { programmes }\end{array}$ & $\begin{array}{l}\text { Lectures, cultural hour and } \\
\text { lunch-hour seminars (Wednesday } \\
\text { afternoons once a month) }\end{array}$ & \multirow[t]{4}{*}{$\begin{array}{l}\text { Meetings and resource sharing } \\
\text { between nursing faculty staff from } \\
\text { different locations }\end{array}$} \\
\hline & & & $\begin{array}{l}\text { Faculty Assembly (first Saturday), } \\
\text { although time and day difference } \\
\text { could be a problem }\end{array}$ & \\
\hline & & & $\begin{array}{l}\text { Lectures organized by Research } \\
\text { Department, Special Lecture Series } \\
\text { and AKU-IED }\end{array}$ & \\
\hline & & & $\begin{array}{l}\text { AKU 25th Anniversary Planning } \\
\text { Committee Meeting }\end{array}$ & \\
\hline \multirow[t]{4}{*}{$\begin{array}{l}\text { Expected } \\
\text { outcomes }\end{array}$} & \multirow{4}{*}{$\begin{array}{l}\text { Identify problems relevant to the } \\
\text { implementation of Elluminate Live in } \\
\text { order to plan for wider } \\
\text { implementation of Elluminate Live at } \\
\text { AKU-IED }\end{array}$} & $\begin{array}{l}\text { Skill enhancement of the faculty, } \\
\text { staff and students }\end{array}$ & $\begin{array}{l}\text { Attendance at meeting, seminar or } \\
\text { workshop that would otherwise have } \\
\text { been missed }\end{array}$ & $\begin{array}{l}\text { Number of online teaching sessions } \\
\text { using live teaching tools }\end{array}$ \\
\hline & & $\begin{array}{l}\text { User satisfaction (through the help } \\
\text { of feedback forms) }\end{array}$ & \multirow{2}{*}{$\begin{array}{l}\text { Work closely with other AKDN } \\
\text { institutions to share intellectual or } \\
\text { material resources and strengthen } \\
\text { the relationship with other AKDN } \\
\text { entities }\end{array}$} & \multirow{3}{*}{$\begin{array}{l}\text { Evaluation of online tools by } \\
\text { moderators and participants for } \\
\text { online learning } \\
\text { Identifying problems with online } \\
\text { learning in different locations }\end{array}$} \\
\hline & & & & \\
\hline & & & $\begin{array}{l}\text { Follow-up with students and } \\
\text { distance education }\end{array}$ & \\
\hline
\end{tabular}


In practice, the programme was under-utilized by the professionals in Dar-esSalaam. Over a 3-year period, approximately 80 teleconsultations occurred, whereas the estimated number of consultations at the time of the launch was 2500 . The main reasons for this underutilization were insufficient bandwidth for an effective Internetbased education programme, discomfort among Dar clinicians in Dar-es-Salaam due to inadequate exposure to the use of computers, and practice behaviours and the environment preventing the use of technology to its fullest capacity. The evaluation team found that the leadership at the Aga Khan Hospital in Dar-es-Salaam was very positive with respect to the use of technology for the training of health care providers. This led to the new programme of remote access for health care professionals that has been described above.

\section{Teleradiology link}

The AKUH in Karachi has a partnership with the French Medical Institute for Children (FMIC), which is an 85-bed paediatric hospital in Kabul. The primary aim of the telemedicine project was to provide access to high-quality diagnostic services. As a first step, the project used broadband technology and wireless video consultation with digital image transfer to provide teleradiology services. CT scans and X-ray images can be diagnosed and interpreted and treatment can be suggested from Karachi. A combination of fibre-optic and radio links is used to transfer images from the FMIC to the AKUH in Karachi (Figure 27.1). Four or five images are transferred to the AKUH every day, and reports are sent back to the FMIC in less than 24 hours.

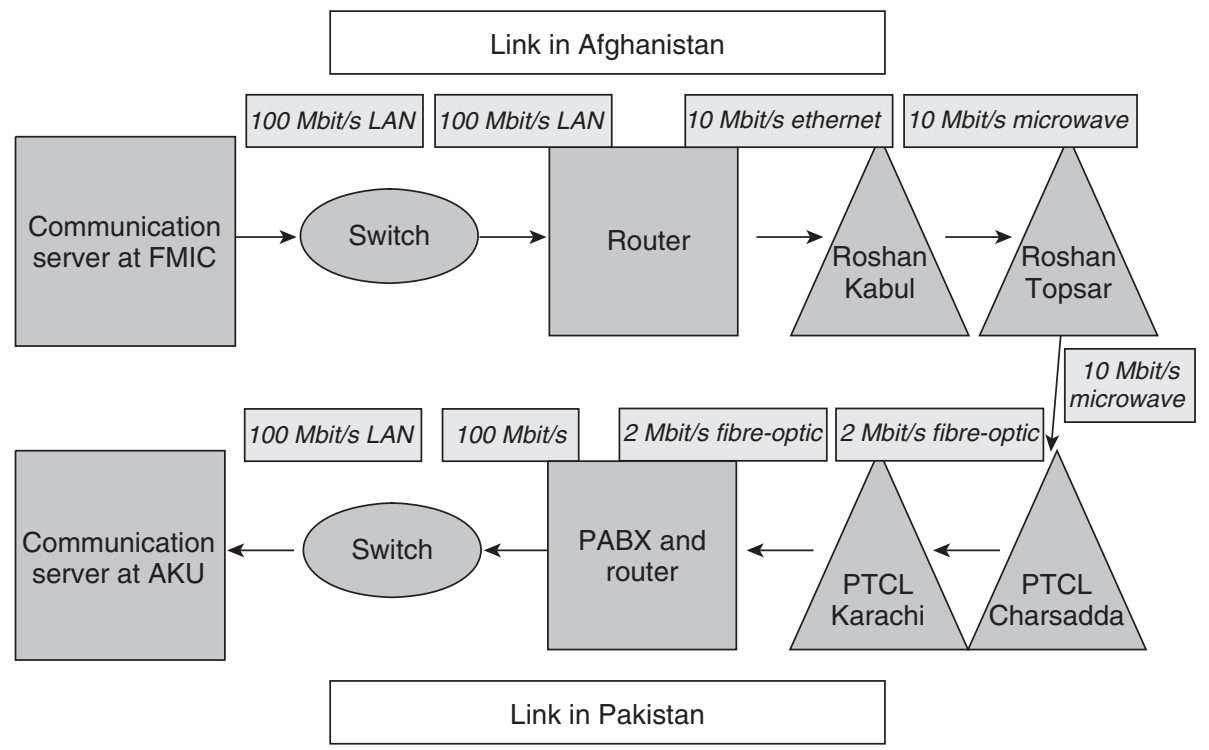

Figure 27.1 Teleradiology link between the French Medical Institute for Children, Kabul and the Aga Khan University Hospital, Karachi 


\section{Information exchange}

Since its inception, the AKU has made patient information available to all care providers, while being careful to maintain the confidentiality of patient records. Several programmes have been introduced to capture medical information electronically and make this available in all patient care areas. Laboratory records, radiology reports, nursing and physician records and order entries, and several types of administrative information have been computerized for rapid access by all care providers. There are still several missing elements, such as physician notes, outpatient records, decision support systems and sharing of patient records between campuses. The university has therefore developed a detailed plan to achieve this. The ultimate goal of electronic health records is to integrate computerized medical records and ordering systems with routine care, and avoid any duplication of work in the form of generating paper records. This will lead eventually to a paperless organization where all information will be available in electronic form, guided by policies to ensure privacy and confidentiality of patient data, yet ensuring rapid access to information for the care providers.

\section{Opportunities and challenges}

The above examples of e-health work show that the AKDN has increased the availability of learning resources, health care and information for its own institutions, with a view to making health services more affordable and accessible in the developing world generally. E-health also offers opportunities for the network institutions to build on each other's strengths and expertise by sharing knowledge, expertise, best practices and information. For example, the doctors and nurses in East Africa possess specialist knowledge and skills in certain tropical diseases, which could be shared with doctors and nurses in other institutions of the network. Such collaboration is likely to encourage the development of a strong knowledge base founded on indigenous, culturally sensitive, e-health applications.

No innovation is free of challenges, especially if it involves bringing a change in the everyday practices, attitudes and beliefs of people. Stemming from the use of new technologies for e-health, there are challenges associated with the development, delivery and sustainability of such programmes. For instance, the above examples represent the efforts of small groups of doctors and nurses from the AKU and the AKHS who are enthusiastic about the use of ICT for learning and are also familiar with modern technology. However, there is a wide spectrum of technological access and expertise among other potential users. Likewise, expertise in teaching and learning, providing patient care and sharing information through technology also vary considerably between the network institutions. Moreover, since there has been no previous experience of such programmes among the participating institutions, there are no formal polices and procedures to guide the implementation. Furthermore, in most cases, no systematic evaluation has yet been conducted to assess the outcomes. While funding for the current projects has been provided through the AKDN, the availability 
of funds for future research, development and evaluation of e-health applications could represent a problem. Clearly, there is a need for network-wide resource sharing, accountability and coordination for the development and implementation of e-health programmes, policies and strategies for AKDN institutions.

\section{Next steps}

To enhance the use of e-health in the AKDN, it is important to develop a network-wide strategy for e-health. Such a strategy would allow collective learning and sharing of knowledge and experience among people providing health care within the AKDN. To develop a network approach to e-health, the following principles have been proposed:

- E-health initiatives should increase access to health care information and services for communities, and enhance the quality of care among network institutions and partners through knowledge transfer and educational programmes.

- E-health initiatives should address the needs of health care institutions, identified and prioritized using sound techniques. The prioritized needs should also guide external institutions and health care professionals interested in working in the field of e-health to focus on interventions addressing the most important health needs of the community.

- All e-health initiatives for the network and partners should ensure that knowledge and experience gained from these projects are measured, and that the results are disseminated to the broader community.

- All e-health initiatives should be standardized and planned to enhance networking among AKDN institutions and partners.

- E-health initiatives for the network and partners should identify suitable platforms and systems that have universal applications. Proprietary software should be avoided whenever possible.

- E-health initiatives should promote collaboration with other partner institutions, especially public institutions, without compromising the quality of care or the safety and confidentiality of patients receiving services from AKDN institutions.

- All e-health projects should focus on the sustainability of the initiatives by demonstrating a return on investment and integration with the existing programmes.

To confirm the above principles, a process of needs and readiness assessment has been started in all the countries where the AKDN operates. This will:

- identify the current and future needs of health care institutions that can be addressed by using e-health

- define the available alternatives and provide justification for the use of e-health

- determine the infrastructure, awareness, willingness, capacity, sociocultural environment and institutional polices required for e-health

- define the process of e-health planning leading to enhanced readiness of health care institutions in the relevant countries

- develop a model for e-health needs and readiness assessment for AKDN institutions and partners in other countries (and for other similar institutions). 
The needs and readiness assessment exercise is currently being carried out in Tanzania and Afghanistan. These two countries were selected based on their needs and existing collaborations between network institutions. The readiness assessment is focusing initially on teleconsultations and tele-education. However, the needs assessment will capture institutional needs in information and knowledge management as well.

The following activities are being conducted during the needs and readiness assessment exercise in the two countries:

1. Developing a stakeholder team in each country. Separate teams of key stakeholders are being formed in each country to plan the needs and readiness assessment in these countries. The stakeholder team decides on the process of needs and readiness assessment by identifying the relevant instruments, supervising data collection and compiling results for guiding e-health implementation in each country.

2. Training the stakeholder team in each country. Once the teams have been formed, the members will be exposed to e-health terminologies and concepts. These are required to carry out the planning of needs and readiness assessment. The training programmes in each country will last for two days each.

3. Conducting the needs assessment in AKDN institutions. Identifying the needs of AKDN institutions that could be addressed though e-health will be conducted using (i) discussions with the stakeholder team members to document their views and suggestions and (ii) focus group discussions with different groups of health care providers and managers of health care institutions. The participants for focus group discussions will be identified by the stakeholder team, and the sessions will be conducted by team members from AKU.

4. Identifying appropriate e-health solutions for the suggested needs. On the basis of the identified needs, appropriate e-health solutions will be selected by the stakeholder team. The process will be carried out in consultation with the team from the AKU and a consultant. Efforts will be made to identify simple, low-cost, lowbandwidth and culturally sensitive e-health solutions for AKDN institutions.

5. Prioritizing e-health solutions. In the next step, the stakeholder team will prioritize the e-health solutions. This step will help in assessing and building the readiness of health care institutions for the e-health applications that have been identified, and avoid wasting time on applications that may not be required in the short term.

6. Conducting readiness assessment of network institutions. Finally, the stakeholder team will choose among the existing tools for e-health readiness assessment that have already been validated and tested in developing countries. The teams will also finalize the plan for analysing the information collected.

\section{Conclusion}

The AKDN represents an interesting example of agencies and institutions working in several different countries towards a common development goal. Health is a 
component of the overall development of the communities, which makes it necessary for the health care institutions to build strong relationships with institutions involved in other facets of development. Better coordination within, among and between these agencies, and with the communities, is necessary for provision of health care in these countries. E-health offers great potential to enable a network of this size to achieve its goals of better access and high quality of care, while operating within the available resource constraints.

The AKDN has developed a plan to move from pilot trials to routine operations, by developing a network approach guided by an overall strategy. The strategy is based on the principles of needs and readiness assessment, community and community-centeredness, knowledge transfer, networking, open platforms, standardization and evaluation. A broad-based needs and readiness assessment has already been started in two countries.

\section{Further reading}

Aga Khan Development Network. Available at: www.akdn.org.

Harambee: Reinforcing African Voices through Collaborative Processes. Available at: www.uneca.org/aisi/picta/HarambeeOverview-v1.pdf.

Ministry of Economic Development, New Zealand. Strengthening Networks and Partnerships. Available at: www.gif.med.govt.nz/aboutgif/networks.asp.

United Nations Development Programme (UNDP). Networks for Development: Lessons Learned from Supporting National and Regional Networks on Legal, Ethical and Human Rights Dimensions of HIV/AIDS. Available at: www.undp.org/ hiv/publications/networks.htm.

United Nations Economic and Social Commission for Asia and the Pacific. Handbook on Strengthening the Women's Information Network for Asia and the Pacific through Computer Networking. Available at: www.unescap.org/esid/GAD/Publication/computer.pdf.

Wiley D. Connecting Learning Objects to Instructional Design Theory: A Definition, a Metaphor, and a Taxonomy. Available at: www.reusability.org/read/chapters/ wiley.doc.

\section{References}

1. Fort V, Obonyo B, Madhavan S. Strengthening the Institutional Capacity of Aga Khan Health Service, East Africa's Community Health Department to Support Organizations Working in Community Health Service. Available at: pdf.dec.org/pdf_docs/Pdacf019.pdf.

2. Aga Khan University. Available at: www.aku.edu.

3. Library of Images, Aga Khan University. Available at: loi.aku.edu/loi.

4. Joint Information Systems Committee (JISC). Circular 7/00: MLE in Further Education: Progress Report. Available at: www.jisc.ac.uk/news/stories/2000/07/circular700.aspx. 